Article

\title{
Promoting Safety Climate Training for Migrant Workers through Non-Technical Skills: A Step Forward to Inclusion
}

\author{
Martina Morando ${ }^{1, * \mathbb{D}}$ and Leonardo Brullo ${ }^{2}$ \\ 1 Section of Psychology, Department of Educational Sciences, University of Catania, 95124 Catania, Italy \\ 2 Section of Psychology, Fo.Co. Onlus, 97012 Chiaramonte Gulfi, Italy; leonardobrullo@coopfoco.org \\ * Correspondence: martina.morando@phd.unict.it
}

Citation: Morando, M.; Brullo, L. Promoting Safety Climate Training for Migrant Workers through Non-Technical Skills: A Step Forward to Inclusion. Merits 2022, 2, 26-45. https: / / doi.org/10.3390/ merits2010004

Academic Editors: Antonino Callea and Hyo Sun Jung

Received: 31 December 2021 Accepted: 14 February 2022 Published: 21 February 2022

Publisher's Note: MDPI stays neutral with regard to jurisdictional claims in published maps and institutional affiliations.

Copyright: (C) 2022 by the authors. Licensee MDPI, Basel, Switzerland. This article is an open access article distributed under the terms and conditions of the Creative Commons Attribution (CC BY) license (https:// creativecommons.org/licenses/by/ $4.0 /)$.

\begin{abstract}
Currently, the number of migrant workers is significantly high and represents a global issue. The impact of the negative aspects of employment and psychosocial risk factors in the workplace on migrants' health and well-being has been underestimated. This study focused first on a perceptions analysis of the diversity climate, safety climate and experiences of discrimination of migrant workers, and then on testing whether and how the contents and meanings of ad hoc training were transferable and transferred to their workplace. Through a program of 4 phases (pre-screening, intervention, assessment and follow-up) and a series of interviews and focus groups, 24 participants were recruited for the study. Consistent with literature, the findings confirmed a poor perception of diversity and safety climate, and several discrimination experiences. The training outcomes showed an improvement of the individual perception of safety, motivation and self-efficacy. In contrast, the work context is still perceived as closed and constraining, which makes complete transferability hard to achieve. Results are quite encouraging and bear out the need for training and the first positive effects on working conditions and quality of life. This study is one of the first attempts in Italy to integrate the analysis of migrants' labor situation, training and its evaluation. Future studies are required.
\end{abstract}

Keywords: safety training; migrant workers; inclusion

\section{Introduction}

Migration is currently a global issue, with international migrants accounting for 3.5\% of the world's population and almost 272 million globally (International Organization for Migration, 2019). The foreign resident population in Italy as of 1 January 2021 amounted to 5 million; compared to 2020, it remained substantially stable ( -4 thousand; $-0.1 \%$ ). The community with Romanian citizenship is the most numerous (1.145 million). They are followed by the Albanian community (422 thousand) and the Moroccan community (414 thousand). Due to the size of these numbers in our context, it is interesting to carry out a study that can take into account this specific category of workers. This study represents one of the first attempts to integrate the analysis of migrants' labor situation, training and its evaluation. Most of the studies on this subject have been conducted overseas and specifically in the construction sector. Our study, although in the early stages of exploration, tries to offer a broader view of other professions in our context. Future studies are certainly needed.

With a view to normality and according to the norms of integration and inclusion, migrant citizens have gradually integrated into the various aspects of society, approaching the working culture and policies of each host country. Thus, culturally diverse workplaces have become the norm rather than the exception in many Western countries, including the United States, Australia, the United Kingdom and most European Union member states [1]. Furthermore, there is a growing awareness that inclusion could represent an advantage on an organizational level and companies must understand that today's workforce is extremely diverse [2]. 
Currently, the number of migrant workers is significantly high, and international migration has become an important part of global, social and economic development. Migrant workers become a valuable resource, as they are empowering and developing the economies of host countries simply by providing their physical and cognitive resources. In Italy in 2020 there will be slightly more than 4 million foreign citizens of working age, i.e., between the ages of 15 and 64. The number of working people is just over 2 million, while job seekers are more than 300,000 [3].

Discussing the topic of work among migrants is important, as employment is one of the most important indicators of integration and independence for these individuals.

Several studies have focused on the analysis of the positive consequences that work has on these specific workers, but there is still a part of this phenomenon that has not been widely investigated. In effect, the negative aspects of unemployment, or the specific difficulties of these workers, are still little covered. The current literature on the topic revealed the positive impact of certain factors on migrants' working conditions: such as living in rural or regional locations [4], gender [5] and country of origin [6].

There is also a growing volume of literature dealing with the difficulties associated with the discrepancy with one's employment aspirations [6], and the difficulties that have arisen with employment and training barriers $[7,8]$.

However, little attention has been paid to the search of the factors that contribute to employment and psychosocial risk factors in the workplace that may affect refugees' psychological health and well-being. Migrant workers more frequently are experiencing significant difficulties in obtaining employment $[9,10]$, more often experience fear of work loss, are more prone to abuse and discrimination, have more difficulty perceiving an adequate sense of belonging in the workplace and having their rights respected, have reduced sociability, and generally do not have a very high quality of life [11-13].

The present study aims to describe and investigate the phenomenon of migration's work, focusing on the specific difficulties and on the promotion of a positive safety climate through a training program. Through a series of interviews and focus groups with privileged participants, this study aims to identify whether and how a training action based on the principles of safety climate could contribute to better well-being for migrant workers, to a better social adaptation and to a general inclusion.

\section{Theoretical Framework}

\subsection{The Concept of Diversity Management and Diversity Climate}

It is well known that the increase of migration across Europe requires the development of appropriate methodologies for both social and work integration. If companies do not adopt policies and practices that encourage the positive integration of employees with different backgrounds, the risk is to leave behind a concrete competitive advantage that is present in other organizations. In the past, some organizations took for granted the greater relevance of dominant groups by treating women and ethnic minorities within companies as unknown and strangers $[14,15]$. In today's organizations, employers and employees tend to be more open to diversity inside their own companies. Therefore, there is an increasing debate on Diversity Management and Diversity Climate [16-18], as constructs to strive for in a logic of globalization and decent work. Diversity Management refers to the proactive voluntary efforts by organizations to create "greater inclusion of employees from diverse backgrounds in formal and informal organizational structures through deliberate policies and programmes" [19] (p. 235). It has been suggested by previous studies how diversity practices could generate positive outcomes for organizations such as increased profitability, creativity, flexibility, and individual and organizational growth [20], as well as generate a climate of greater social cohesion and team working. This is why organizations and employees need to work together to provide a climate of trust and inclusion through real actions in the workplace in order to achieve competitive advantages.

The construct of diversity climate, on the other hand, is related to that of organizational climate, which has a direct impact on employees' behavior and in particular on 
job satisfaction and the quality of performance. There are two main definitions of this concept: Mor Barak et al. [21] define it as "employee behaviors and attitudes that are grounded in perceptions of the organizational context related to women and minorities" (p. 83); Chrobot-Mason and Aramovich [22] define it as "consisting of perceptions of a set of diversity practices aimed at providing fair and equal opportunities to all employees" (p. 663). Furthermore, several scholars have assumed that the diversity climate also consists of the interpretation of such practices. Diversity practices in a firm operate as a signal of its commitment to supporting employees of all backgrounds. A successful diversity program should communicate its goals as a challenge and an opportunity rather than a threat or obstacle to be overcome $[23,24]$.

The perception of a fair diversity climate has a direct impact on the work performances of groups, with particular relevance to minority groups [25]. In any organization, it is therefore worth implementing diversity management policies and cultivating a diversity climate. Given that, it is interesting for our study to examined migrants' perceptions of the diversity climate and more generally of their experiences of discrimination in their working environments. Our aim is to obtain detailed information on migrants' perceptions of the practices and policies adopted in their workplaces, whether these foster fair and equal working environments or, on the contrary, a hostile and discriminatory climate prevailed. In addition, we investigated the effect that these policies and practices have on the psychological well-being of the migrant worker and on his or her work performance.

\subsection{Safety Conditions of Migrant Workers}

Given the global importance and numerical size of the migration phenomenon, the need for research and policies that take into account the specific needs and capacities of migrant workers has emerged in recent years.

Despite integration policies and support systems for migrants (including asylum seekers/refugees) existing in many Western countries [26], many migrant workers live in a precarious situation with adverse working conditions. Indeed, migrant workers are among the most vulnerable members of contemporary society, which sees them as those who face the most difficulties and suffer the highest levels of injustice [27]. The jobs they perform are often the dirtiest, most dangerous and demanding (sometimes even degrading or humiliating), and they often experience the paradox of having to be grateful for such jobs [28]. They are also often abused, hidden from the public and the law, and subject to prejudice and stigma by some members of the population [29]. They also work for significantly lower salaries than average, and compared to native workers have longer and more exhausting working hours, and often work and live in worse conditions than nonimmigrants. They constantly experience human rights violations, abuse, human trafficking and violence, but continue to work out of fear and as a way of livelihood and independence.

However, one of the most problematic issues for these workers is related to safety. For these workers, there is not just a lack of perception of the safety climate, but often there is an absence of safety training. Workplace safety climate refers to the perceptions that workers share about safety policies, procedures and practices [30,31]. It is an important construct because it represents a "key intersection between organizational and psychological processes" and is an important index of organizational support and effects on individual workers [32]. Workplace safety climate has a direct and positive effect not only on workers' health and safety [33], but on work engagement, performance and stress levels; it is also a predictor in the sense of protection against workplace accidents [34].

Recent empirical evidence has shown that migrant workers face greater risks at work, and work without adequate training and without the mandatory protective equipment. They also often have their rights violated as people and workers but avoid complaining since they do not have work authorization, or they feel at risk of losing their jobs or even being deported. In Italy, the analysis of accidents by mode of accident revealed that the percentage of accidents by migrants in 2020 occurred during the exercise of the work activity, and that this percentage is slightly higher than that of Italian workers [3]. 
These data confirmed that there are different risks faced by migrant workers and that a targeted and specific training program could be a possible solution to solve the specific difficulties [3].

The specific constraints that migrants workers face are: a generally poor understanding of relevant employment laws (e.g., workplace health and safety, unfair dismissal) [35] and language barriers, which make them powerless to change adverse working conditions; a challenging relationship between trade unions and migrant workers, which lead to acceptance of lower wages and less favorable working and employment conditions [36,37]; a large proportion of specific types of employment, such as short-term, temporary and precarious contracts [38], which generate a feeling of job insecurity; and a higher probability than native workers to be exposed to high temperatures, loud noises, strong vibrations and fast work speeds, and to stand for long periods of time. In general, they are involved in jobs that are physically demanding, safety training may be missed, and they often experience workplace abuses, including delayed payment, sexual harassment, withholding of food and discrimination $[39,40]$. For all these reasons, it was important to sample migrant workers' perception about the safety climate, i.e., whether they actually felt supported and protected from a security perspective by the organization. This element is very important to be analyzed both in a more technical and psychological sense. Therefore, the primary aim was to examine whether they perceived support and attention on security issues from their organization.

\subsection{The Analysis of Risk Factor of Migrant Workers}

Adverse health and safety outcomes disproportionately affect migrant workers around the world: there are multiple reasons why immigrant workers carry this greater risk compared to native workers.

In general, migrant workers work in high-risk work contexts that expose them to worse conditions and risks. The precarious nature of their contracts also makes them susceptible to feelings of insecurity and negative psychosocial effects such as depression, workaholism, reduced job satisfaction and poor performance. They are not represented and defended by trade unions, and often do not know the rules and rights to which they are entitled [41].

Another important element of risk to the health and safety of migrant workers is the limited or lack of the host country's language [42]. Limited language skills in fact lead such workers to be more likely employed in physical work, which carries more risks and injuries $[43,44]$. In addition, language barriers affect working conditions in two ways: on the one hand, they are a means of discrimination because training courses, posted safety information, and warning signs are exclusively provided in the language of the host country, generating confusion and difficulties in non-native speakers; on the other hand, these barriers are a sort of cultural filter in the correct interpretation of the safety regulations, leading to greater risk exposure of migrants who have not correctly assimilated these regulations [45-48]. As a result, they have low or any perceptions of safety climate $[27,41]$.

The health and safety threats to migrant workers also depend on various abuses in the workplace. These take many forms, from outright physical abuse or harassment to what has been known as benign neglect, i.e., managers' failure to implement safety measures and workers' failure to comply with them [49]. The perception of not feeling protected generates significant psychological effects and negatively affects the psychological contract between the organization and workers [39,50].

A number of studies showed the negative effects of such abuses: Preibisch and Otero [44] in a series of interviews with Mexican and Indian immigrants in Canada reported that constant threats of physical violence and exposure to verbal abuse contributed to workers' acquiescence to working longer hours or in unsafe conditions. In contrast, a qualitative study of Latino hotel workers reported that immigrants were more affected by various incidents of disrespect, unfair work assignments and verbal abuse from managers [51]. 
Moreover, in a study from Portugal reported that immigrant domestic workers frequently experience workplace abuse, including late payment, sexual harassment, food refusal and discrimination [52].

Migrant workers often experience difficulties with health care and general healthrelated conditions. Due to unstable working conditions, poverty, lack of documentation and incomplete knowledge of language and rights, they experience greater difficulty in taking care of themselves. Special conditions such as long work hours, including nights and weekends without paid vacations, make it impossible for workers to access health clinics during standard working hours, and language difficulties and reduced sociability reduce their ability to consult medical professionals and avoid exacerbating medical situations. This causes them to experience real conditions of presenteeism (for fear of losing their jobs), and for a variety of reasons they do not require respect for their healthcare rights in the workplace.

In order to understand the quantification of the risk factor for migrant workers, a further objective of the current study is to investigate the number and topic of previous training programs, the knowledge about trade unions, labor rights and types of contracts, and awareness and use of personal protective equipment. This objective is crucial for this study as it not only provided an analysis of the training needs of this specific sample, but also served as an indicator of possible training needs for similar studies.

\subsection{Safety Training as a Way to Overcome Migrant Workers' Challenges in Safety}

The topic of safety training is as relevant as it is timeless. It is a key mechanism for improving the safety climate, enhancing worker performance, and reducing accidents and injuries. Few studies have focused on the topic of safety training for migrant workers, as it is complex, specific and more difficult to evaluate. Peiro et al. [40] identified some specific problems with these training programs, mentioned above, such as the apparent lack of available training, particularly at lower and elementary levels and/or the lack or absence of adequate language skills [53]. These categories of workers also seem to be more responsive to the so-called Matthew effect [54], which suggests that those with a lower level of education and in need of more training are the least receptive.

Several strategies have been implemented to deal with these problems and situations. Specifically, considerable attention is directed towards overcoming language barriers and on the content of training programs. To overcome the Matthew effect, it is instead necessary to act by making workers pro-active, directly promoting motivation and participation in training. Training programs should be implemented and organized in accordance with the conditions and characteristics of migrant workers, ensuring that they could learn knowledge and skills, and gain an understanding of attitudes and behavior relevant to improving individual safe behavior and interactions with others. Following this rationale, training interventions and possible facilitators of training transfer are mainly cognitive, personality traits and psychological skills such as conscientiousness, neuroticism, selfefficacy, learning goal orientation and motivation [55].

The safety training contents for migrants require specific characteristics. Considering the gaps and characteristics of this category of workers, it seems appropriate to calibrate interventions focusing mainly on legislation and technical safety skills [56,57]. As evidenced by Vignoli et al. [58], in addition to a more technical training, it is vital for the migrant workers' safety to include specific training on some soft skills, such as risk awareness and intercultural communication $[59,60]$. Knowing how to adequately communicate and discuss safety risks, and promoting and enhancing teamwork as an element of cohesion and collective safety, are some of the typical topics that a training for migrants should have.

Safety training is important because it directly affects the behaviors of workers, who are responsible for more than $80 \%$ of workplace accidents [61]. The importance of training for migrant workers is recognized by both parties, who benefit from the increased awareness and knowledge of workers, making the work environment healthier, safer but also effective and efficient in performance. However, designing and implementing effec- 
tive safety training programs for migrant workers has posed complications that must be addressed $[58,62,63]$.

The first issue relates to the measurability of the intervention and whether the learning could actually be transferred to the workplace. Only one study explored the deliverable training effect, i.e., whether trained migrant workers transfer the skills and knowledge acquired through training [62]. The experimental results of this study suggested that training with additional interventions may impact both the knowledge transfer during training sessions and the training transfer in the workplace. The use of different learning styles, inclusion of bilingual training, additional organizational support, and cultural exchange were just a few of the strategies that can maximize training and increase the possibility of the on jobsite application [64].

The second issue concerns the target audience and scope of the training intervention. For a training intervention to be truly effective, it is necessary to involve both migrant workers, their non-migrant colleagues and, above all, all stakeholders and interested holders. That becomes crucial because a really useful and successful training arises from the sensitivity of the social environment around that delivers, conceives and requires the training. Exploring the sensemaking of the stakeholders in relation to migrant worker safety training, could help us to understand the core meanings they attribute to the challenges and opportunities that such training might have [58].

For these reasons, this study had the additional objective of assessing the efficacy of a training intervention aimed at migrant workers on issues related to safety and some soft-skills. In detail, in order to grasp some of the problems related to the intervention's measurability and the transferability of its contents, it was decided to implement certain training techniques and carried out two separate evaluations at two different times. In this way, it was possible to pursue the goal of assessing learning at the end of the training intervention and measure the actual applicability and transferability after months.

\subsection{The Purpose of the Study}

The general aim of this study is to investigate the efficacy of safety and soft-skills training for migrant workers, on their working conditions and in general on their well-being and quality of life.

Specifically, the study focused first on the analysis of their perceptions of diversity climate, safety climate and experiences of discrimination, and then on testing whether and how the contents and meanings of the training were transferable and transferred to the workplace, through attitudes and behaviors such as participation, awareness and voice promoting behaviors, better social adaptation and perception of inclusion.

Although the nature of the study is exploratory, starting with previous literature and local knowledge, it was hypothesized that:

Hypothesis 1 (H1). Migrant workers experienced high levels of discrimination in the workplace and perceived an unfair and unequal climate, thus at the detriment of an adequate diversity climate.

Hypothesis 2 (H2). Migrant workers perceived inadequate attention and support from their organization regarding safety issues.

Hypothesis 3 (H3). Migrant workers reported a lack or incomplete knowledge of language, safety contents and labor rights, reflecting an increased risk to their physical and psychological health and safety.

Hypothesis 4 (H4). A training intervention designed and implemented ad hoc had satisfactory results for migrants in terms of motivation and participation and sedimentation of content.

Hypothesis $\mathbf{5}$ (H5). The transferability of training content is difficult but still possible. 


\section{Materials and Methods}

\subsection{Methods}

As there are a limited number of specific studies on the topic in the literature and in the Italian context, the methodological approach selected for this research project was qualitative, as it was considered particularly useful in this specific exploratory phase of the phenomenon. This approach was also selected considering the target sample, who did not speak the language of the host country and did not have any other language proficiency such as English, French or German: they were not ideal candidates for structured questionnaires on the topic.

The present study was carried out from March 2021 to December 2021 and included four specific phases: an exploratory pre-screening phase conducted in March, a training intervention phase from April to July, a post-training phase in July and a follow-up phase in December.

\subsection{Participants of the Study}

A purposive sampling technique, which involves seeking out "groups, settings and individuals where [...] the process being studied is most likely to occur" [65] (p. 370), was used to recruit and select participants who would provide a rich picture of safety in industry from a range of perspectives.

This study is the result of an initiative promoted by a Sicilian social cooperative (which prefers to remain anonymous) that, recognizing the training needs of migrants, aimed to implement safety training courses to guarantee them greater awareness, protection and social adaptation. Through good teamwork and study, the most appropriate training path proposal was built, offered, and the results were tested in terms of effectiveness and transferability. A total of 24 participants were recruited for the study. They were selected from a larger group who participated in the training program but were not available to participate in a 9-month study. The 24 participants ranged in age between 19 and 26, and were all men, with most of them belonging to two migrant reception centers, located in Sicily. Nine of these workers originating from Somalia, four from Gambia, five from Morocco and six from Tunisia (Table 1). The migrant workers had been in their host countries for 7 months to 4 years, with the majority being resident for at least 2 years. They had worked in their industry for 2 weeks to 2 years (Table 2), and undertook numerous different roles including production operatives, ground workers, painters, steel workers, concrete finishers, joiners and carpenters (Table 3).

Table 1. Information of country of origin of the sample.

\begin{tabular}{ccccc}
\hline & Frequencies & \% & Valid \% & Cumulative $\%$ \\
\hline Somalia & 9 & 37.5 & 37.5 & 37.5 \\
Gambia & 4 & 16.67 & 16.67 & 54.17 \\
Morocco & 5 & 20.83 & 20.83 & 75 \\
Tunisia & 6 & 25 & 25 & 100 \\
Total & 24 & $100 \%$ & $100 \%$ & $100 \%$ \\
\hline
\end{tabular}

Table 2. Socio demographic and background information of the sample.

\begin{tabular}{cccccc}
\hline & $\mathbf{N}$ & Min & Max & M & S.D \\
\hline 1. Age & 24 & 19 & 26 & 22.67 & 0.87 \\
$\begin{array}{c}\text { 2. Length of time in the host } \\
\text { country (expressed in months) }\end{array}$ & 24 & 7 & 48 & 26 & 13.78 \\
$\begin{array}{c}\text { 3. Timelines in the work sector } \\
\text { (expressed in weeks) }\end{array}$ & 24 & 2 & 104 & 30 & 27 \\
\hline
\end{tabular}


Table 3. Professional roles of the sample.

\begin{tabular}{ccccc}
\hline & Frequencies & $\mathbf{\%}$ & Valid $\%$ & Cumulative $\%$ \\
\hline Production operatives & 2 & 8.33 & 8.33 & 8.33 \\
Ground workers & 7 & 29.17 & 29.17 & 37.5 \\
Painters & 5 & 20.84 & 20.84 & 58.34 \\
Steel Workers & 2 & 8.33 & 8.33 & 66.67 \\
Concrete finishers & 4 & 16.67 & 16.67 & 83.34 \\
Joiners & 2 & 8.33 & 8.33 & 91.67 \\
Carpenters & 2 & 8.33 & 8.33 & 100 \\
Total & 24 & $100 \%$ & $100 \%$ & $100 \%$ \\
\hline
\end{tabular}

\subsection{Data Collection and Instrument}

Data were collected at local migrant reception centers between March and December 2021, via three focus groups (8 participants per group) and 24 semi-structured interviews [66]. These methods were chosen for their flexible nature, allowing the same topics to be addressed with all participants while also enabling probing of arising areas of interest [67]. All the focus groups and the interviews were carried out with the support and the help of cultural mediators, to favor a more fluid communication. It was believed that semi-structured interviews were appropriate for collecting information from workers for several reasons: the confidentiality of responses could be guaranteed, and the overcoming of constraints and linguistic requirements was easier to achieve with the help of these tools. In addition, the focus group technique $[68,69]$ was considered particularly appropriate for this purpose, allowing us to gain more depth to the analysis carried out and assume more complex and complete information related to motivations, attitudes, habits, experiences and expectations in the work context and personal situation.

The four phases that constituted the present study are fully described in the following sentences and summarized in Table 4.

Table 4. Summary of the four phases of the study.

\begin{tabular}{|c|c|c|c|}
\hline Phase & Technique & Application & Contents \\
\hline 1st Phase & Focus group & $\begin{array}{c}8 \text { persons in } \\
3 \text { different } \\
\text { sessions }\end{array}$ & $\begin{array}{l}\text { background information; in-depth } \\
\text { information related such as: } \\
\text { discrimination, organisational support, } \\
\text { diversity and safety climate, previous } \\
\text { training programs, awareness and use of } \\
\text { personal protective equipment }\end{array}$ \\
\hline 2nd Phase & $\begin{array}{l}\text { Training } \\
\text { Program }\end{array}$ & $\begin{array}{l}\text { In presence } \\
\text { learning; bilingual } \\
\text { approach; } \\
\text { linguistic } \\
\text { mediator }\end{array}$ & $\begin{array}{l}\text { situational awareness, communication, } \\
\text { teamworking, decision making and stress } \\
\text { and fatigue management, relationship } \\
\text { and significance of trade union, } \\
\text { knowledge of labor rights and type } \\
\text { of employment. }\end{array}$ \\
\hline 3rd Phase & $\begin{array}{c}\text { In deep } \\
\text { interviews }\end{array}$ & $\begin{array}{l}\text { One to one } \\
\text { approach }\end{array}$ & $\begin{array}{l}\text { Assessment of motivation or intent to } \\
\text { transfer content training on the job site; } \\
\text { self-efficacy post-training; support and } \\
\text { organizational constraints; learning of the } \\
\text { training contents. }\end{array}$ \\
\hline 4th Phase & $\begin{array}{c}\text { In deep } \\
\text { interviews }\end{array}$ & $\begin{array}{l}\text { One to one } \\
\text { approach }\end{array}$ & $\begin{array}{l}\text { Same measure of the 3rd phase and } \\
\text { assessment of actual use of the } \\
\text { knowledge of the trainings in the } \\
\text { everyday working life; implementation } \\
\text { of proactive and promoting voice } \\
\text { behaviours, and the perception of a better } \\
\text { social adaptation and quality of life }\end{array}$ \\
\hline
\end{tabular}




\subsection{First Phase: Exploratory Pre-Screening Phase}

In the first phase of this project, an analysis of the working conditions, well-being and quality of life of the migrant workers involved in the study was carried out. To obtain this information the focus group technique was used, dividing the participants into groups of 8 persons in 3 different sessions. The session lasted $90 \mathrm{~min}$. All sessions were video-recorded, with permission, to facilitate transcription and allow the interviewer to fully engage with the participants. Each focus group session involved the collection of the same information:

(1) Background information (e.g., nationality, length of time in the host country, experience and timelines in the work sector).

(2) In-depth information related to the topic, such as discrimination, organizational support, diversity and safety climate perceptions, life satisfaction, psychological and occupational distress, depression, anxiety, need for recovery, number and topic of previous training programs, knowledge, and number of personal protective equipment [70].

At the end, all focus group answers were transcribed in the host country's language and after textual analysis, the main results were translated into English.

\subsection{Second Phase: The Training Intervention}

The second phase of this project, on the other hand, focused on the fruition of the safety training program for migrant workers. Since this training proposal emerged from a social cooperative and the workers involved were from different work contexts, the training contents mainly covered non-technical skills. The choice of not addressing training topics related to hard skills is also due to the consideration that it is a competence of other organizations in a direct and normative way.

For this reason, taking note of the studies of Flynn et al. [71] and Vignoli et al. [58] we focused the content of the training program on five non-technical skills taken from the taxonomy developed by Flynn and colleagues [71] and we added some new topics: situational awareness, communication, teamworking, decision making and stress and fatigue management [71], relationship and significance of trade union, knowledge of labor rights and type of employment. We used on-site lessons for the explanations of the contents with various training techniques such as role playing for favoring participation and learning process.

Consistent with the findings of Hussain and colleagues [62], various learning techniques were used in order to facilitate the comprehension and long-term transferability of the content. The training was indeed delivered using a bilingual approach: the contents were presented in Italian but also translated and mediated in the various languages through the valuable contribution of the different cultural mediators. Role playing and micro-movies were also used with comments and interpretations on issues of racial and/or cultural prejudice experienced and suffered.

\subsection{Third Phase: Post-Training Phase}

The third phase was carried out immediately at the end of the training in order to test whether learning had taken place [50,72]. In this phase we used the interview instrument. In detail, we aimed to measure individual characteristics, work environmental factors that may trigger outcomes and to establish a baseline of intermediate outcomes, i.e., changes in behaviors related to non-technical skills [64].

In this phase, as individual characteristics, we investigated the motivation or intent to transfer content training on the job site. Most research focused on motivation to transfer before training; however, from our perspective it was interesting to analyze this motivation in the post phase, as the content and methods of the training are likely to influence intention $[73,74]$. We also analyzed the self-efficacy post-training, i.e., the degree to which the trainees believe they can successfully overcome obstacles on the job. Huang et al. [75] suggested that these individual features affected learning and the motivation to transfer. It 
is also measured the awareness about the shared contents and the knowledge achieved. For work environmental factors, these were investigated: transfer climate, support and organizational constraints. Transfer climate is operationalized as safety climate and measured at baseline in phase 1, with a sentence to assess the issue with a scale from 1 to 10 .

To understand non-technical skills important for ensuring safety among migrant workers, we used the taxonomy of Flin et al. [76]. These skills should be measured immediately after training so that we have a baseline measure for assessing changes over time. In this sense we used as a guideline the measure instrument proposed by Mariani et al. [64]. During the interviews, it was proposed to measure these skills on a scale from 1 to 10 , indicating how much they are present in one's daily work life. Thus, in this phase we collected and measured the outcomes of the training as an effect of the training itself. In fact, it is more reasonable to use post measures, as trainees are not expected to have engaged in these behaviors before the training, but instead to acquire them gradually through the training.

\subsection{Forth Phase: Follow-Up Phase}

Although there are no fixed recommendations to perform follow-up, the average time found in the meta-analysis by Blume et al. [55] is 14 weeks. For this reason, we proposed this phase from 14 weeks after. Literature reported that twelve weeks should give migrant workers an opportunity to practice a range of safety behaviors and an additional six months is sufficient for behaviors to consolidate [77]. The measured evaluations done in this phase are quite similar to those of the previous phase in order to allow a simple and direct comparison. Some elements have been added during these new interviews, that is: the question about the actual use of the knowledge of the training in the everyday working life; the implementation of proactive and promoting voice behaviors; and the perception of better social adaptation and quality of life [78,79].

\section{Results}

The results emerging from this study are discussed considering the phase division, in order to make what emerged more accessible and clearer.

From the exploratory analysis of phase 1, concerning working conditions, well-being and quality of life in general, the results that emerged from the focus group are very interesting.

On the subject of discrimination, migrant workers more or less unanimously report that they experience and perceive it mainly in the non-work context. They reported episodes and stories of social marginalization and distance, mainly related to social activities and community relations. They often complained about the difficulty of relating to each other outside their protected environments, such as communities or accommodation centers. These findings were consistent with previous studies that confirmed that for minority group members, the potential need to cope with discrimination is an inevitable part of everyday life $[39,80]$.

In relation to work contexts, it seems rather that they experience a feeling of resignation, due to the difficulty of respecting their work aspirations, which often turns into a lack of motivation and spirit of improvement. In the focus group they were aware of the onerous conditions of their working position but reported that they passively accept this precarious working situation for fear of being unable to support their family of origin or of losing their independence. In detail, these answers are mostly provided by ground workers, who have heavier workloads in specific periods.

Some of their answer reported:

"I know that coming to Italy meant doing a different job from the one I did. Without school and language I can only do the jobs you don't want" ("you" meaning Italians).

"My Italian colleagues take more money than me. I am angry about that but I don't say anything. If I say something they don't make me work any longer." 
On this line, they felt less supported by organizations and their bosses, but experienced a deep sense of gratitude to them for offering this opportunity. This is a very interesting element, because it says a great deal about the self-perception and identity construction of migrant workers as individuals, who perceived themselves in a subordinate and inferior position with no apparent reason.

Thus, these findings confirmed hypothesis 1 , that is, the experience of migrant worker discrimination situations in the workplace and also outside [39]. These affected their perception of the diversity climate, although they reported some good supportive relationships with colleagues. Several participants agreed with the sentence of one of them who said:

"I have found some good people who offer me a ride in their car and don't make me walk in the summer heat".

Concerning psychophysical conditions, many of them reported perceiving a lot of fatigue in relation to specific working hours or climatic temperature, but did not associate any psychological or physical symptoms directly with the work situation. Some of them reported that they are aware that in work as in life there are difficulties, but they have to be dealt with and not seen as a limitation. These results are slightly in contrast to some of the literature on the issue, which instead reported in a study on the perceived mental health of immigrants in Italy that they perceive being discriminated at work, as foreign residents, and that this increased the possibility of reporting a worse mental health status. The most common symptoms are states of anxiety, depression, fear, frustration, sense of helplessness, loss of hope, paranoid ideations, resentment, low levels of self-esteem [81,82].

Other studies, however, are quite in line with the findings, i.e., they report that members of minority groups often tend to minimize their personal experience with discrimination, probably mediated by the resignation mentioned above or by the unfounded gratitude they feel $[39,80]$.

On the issue of safety, they reported that they feel quite safe in their workplace but at the same time they reported that they did not receive any training and/or were not aware of the meaning and significance of some safety signs. Given that, they became aware that there was a gap with the safety issue, both from their and their organizations' point of view, which did not seem to care. In this sense they did not perceive a full support by their organization or boss. For these reasons also the $\mathrm{H} 2$ seems to be confirmed.

On the number and topics of other training interventions, workers in the agricultural sector and in some companies related to food production reported that they never had any kind of training, although they often handled products such as pesticides, chemicals and/or special machines. Some of their answers reported:

"I use something on plants, but I don't know what it is. Once I got it in my eye and it hurt a lot."

"Yes, we have helmets for the head but I don't know what it's for...he told me to buy some shoes (safety shoes) but they cost too much and I go with these."

"I did a course, but I didn't understand much. A lot of difficult words in Italian."

Furthermore, as concerns the workers' rights, the various contracts that exist and all related actions in the working environment, there was very limited knowledge. Many migrant workers are often unaware of their type of contract and of whether the pay is in line with the law or not. This is even more pronounced for those who have succeeded in finding a job independently, and who are therefore less protected by the accommodation centers and project workers. These answers and some mentioned before, unfortunately, confirmed also the $\mathrm{H} 3$, that reported for migrant workers a lack or incomplete knowledge of language, safety contents and labor rights, reflecting an increased risk to their physical and psychological health and safety.

In the second phase, the implementation of the actual training intervention, the results that emerged were basically of a good level of participation and interest both in the application and during the proposed activities. As many as 37 migrant workers participated 
in the intervention, but only 24 chose to participate in this study. With the valuable support of the linguistic and cultural mediators and the various learning techniques implemented, we managed to involve the participants and allow them to gain real understanding.

At the end of the training intervention, we measured whether or not learning had occurred in these workers. Through the interviews carried out in phase three we succeeded in collecting some important data. Among the individual characteristics, we measured the intention to transfer this knowledge to their working context. Migrant workers consistently reported a strong motivation to apply and use the knowledge they had learned, as they believe it will be useful for improving their conditions and job performance. Together with this enthusiastic reaction, however, many of them reported fears of non-applicability in their work environments. They are concerned, for example, that merely requesting more breaks or a day off will always put them at a disadvantage and they may risk losing their jobs. In fact, although they are familiar with and aware of the rules on unfair dismissal, they stated that "It's a different story at work"(Jamal). In this sense H4, is partially confirmed for the individual characteristics. It emerged for migrant workers a strong motivation to transfer contents' training on the job site, but in relation to the self-efficacy very low levels were reported, affected by the workplace and employers' knowledge. These data are fully consistent with those proposed by Peiro and colleagues [40] in their systematic review of the training for migrants workers. They stated that the post-training context is equally important and influential, especially for migrant workers who often have a peculiar relationship with supervisors $[35,83]$. Organizational and supervisor support, as well as the opportunity to apply the training immediately on the job, is important for better learning and use of the new knowledge and skills [55,84].

Furthermore, they perceived their working environment as very static and hostile towards themselves. They perceived more constraints and limitations than support and a good safety climate. These data were also very interesting for future interventions: providing specific training and awareness campaigns for stakeholders and organizations and investigating their point of view on these issues could produce many more important and stable effects. However, when measuring the perception of the safety climate, the results were slightly higher than the baseline of phase 1, due to a greater knowledge and awareness among migrants. This construct was measured at baseline in phase 1 , with a sentence that assessed issue with a scale from 1 to 10. It was decided to use this approach to simplify comparison and understanding for the participants. In Table 5 were presented for all the participants the comparison of this perception at baseline and at Time 1 .

Table 5. Comparison of the perception of safety climate at baseline and at Time 1 .

\begin{tabular}{lccccc}
\hline & Baseline & Time 1 & & Baseline & Time 1 \\
\hline Partecipant 1 & 3 & 3 & Partecipant 13 & 3 & 3 \\
Partecipant 2 & 5 & 6 & Partecipant 14 & 5 & 3 \\
Partecipant 3 & 7 & 6 & Partecipant 15 & 4 & 5 \\
Partecipant 4 & 2 & 4 & Partecipant 16 & 6 & 5 \\
Partecipant 5 & 4 & 4 & Partecipant 17 & 3 & 4 \\
Partecipant 6 & 2 & 3 & Partecipant 18 & 1 & 2 \\
Partecipant 7 & 2 & 4 & Partecipant 19 & 1 & 2 \\
Partecipant 8 & 3 & 2 & Partecipant 20 & 2 & 2 \\
Partecipant 9 & 2 & 2 & Partecipant 21 & 3 & 2 \\
Partecipant 10 & 7 & 7 & Partecipant 22 & 2 & 4 \\
Partecipant 11 & 5 & 5 & Partecipant 23 & 3 & 2 \\
Partecipant 12 & 2 & 3 & Partecipant 24 & 2 & 4 \\
\hline
\end{tabular}

On the non-technical skills side, the evaluation included: teamwork (a shared approach to working safely); situational awareness (the ability to identify dangerous situations); communication (communicating hazards); decision-making (deciding how to deal with and manage dangerous situations); and fatigue and stress management (recognizing how being tired and stressed can affect safety behavior). After proper training on each of these 
topics and according to the guideline of the tool proposed by Mariani and colleagues [64], we assessed the level of these skills, using the results as a baseline as a confrontation with step 4. During the interviews, we proposed to measure these skills on a scale from 1 to 10 , indicating how much they are present in one's daily work life.

Concerning team working, the average score reported by migrants was 5.2, a datum that seems to be strongly influenced by the role that many native colleagues play towards migrants: in many cases they are in fact supported by an older and more experienced worker, who more than a collaborator or a promoter of independence, acts as a constant controller. This datum confirmed the strong importance that teamwork had for this category of workers. As stated by Peiro and colleagues [40], social relations were a sort of challenge for migrants. They often had poor relationships with supervisors and experience language or prejudice barriers [35]. Furthermore, they usually worked with people from the same culture. Favoring teamworking with native workers could increase the learning of the safety norms, values, regulations, and language of the host country but also a better inclusion.

As for the awareness of the situation, the average score reported was 2.8, which was verbally explained by the interviewees as a deeper awareness only subsequent to the training. The average score for hazard communication was very low for those who have been in the territory for a shorter time, and slightly higher for those who have been in the territory for more than a year. The knowledge and proficiency of the host language seems to have a significant influence on this result.

Very low scores, averaging 1.9, were reported for decision-making. In their interviews, migrant workers justified this choice claiming to be unable to make decisions at work independently, once again confirming that the working environment was as a real constraint. Similar results were obtained on the management of fatigue and stress: although the interviewees reported being aware that these behaviors involve significant risks, they preferred to complete their work without complaints and to give up leisure activities in order to have more rest. These findings were also confirmed by the study carried out by Mariani and colleagues, and Vignoli and colleagues [58,64].

The results from the fourth phase of this project relate directly to the efficacy and transferability of safety training for migrants in working contexts. In this phase, individual focused interviews also were used, carried out with the help of a linguistic and cultural mediator after a time interval of 14 weeks or more. On the specific issues of this phase, it emerged that: the migrant workers reported that they used the training knowledge and content and benefited from it in their daily work. They also reported to have contacted the trade unions, checked their contracts and negotiated with their bosses about lack of contract and work schedules. In this sense it seems that they learned and implemented voice behaviors, aiming at the joint improvement of working conditions and psycho-physical well-being. They also spontaneously reported that the discussion and confrontation with their colleagues, including on safety issues, encouraged social relations and additional opportunities for interaction and exchanges.

They reported for example:

"I asked my colleagues if they knew of a trade union and I went there."

"I talked to my employer about the possibility of doing a paid internship and then being hired. I explained the law to him..."

On the variables measured in phase three, some of the results were particularly significant. As far as individual characteristics are concerned, no important differences emerged; on the contrary migrant workers are still showing good levels of self-efficacy and motivation in transferability regardless of time passed and the contact with the organizational reality. Related to the environmental factors perceived as constraints, the results unfortunately did not show great changes, instead confirming the anticipated apprehension of migrants. This result brings us to reflect on the importance of a wider training, but also on how a fear and a resistance so strong could actually translate into a sort of self-fulfilling prophecy, in line with a previous study that analyzed this longitudinal effect [63] and the 
other group involvement [58,64]. This result, confirming H5, clearly leads us to think that it is necessary research in these terms and an education program aimed at removing these resistances and prejudices.

The migrants reported higher average scores in team working (6.7), communication (5.1) and situational awareness (4.8) in relation to the non-technical skills baseline. Table 6 summarizes these findings, comparing average score of each skill for the sample. Migrant workers verbally reported that they improved their work with others and their communication, and that it helped them to feel safer and to behave in a fairer and more correct manner. Moreover, the knowledge and awareness resulting from the training made them more confident and in control, increasing the general perception of safety and protection.

Table 6. Comparison of the average score of non-technical skills for the sample.

\begin{tabular}{ccc}
\hline & Post Training & 1st Follow Up \\
\hline Situational Awareness & 2.8 & 4.8 \\
Communication & 3.2 & 5.1 \\
Team Working & 5.2 & 6.7 \\
Decision Making & 1.9 & 2.5 \\
Stress and fatigue management & 2.1 & 4.1 \\
Relationship and significance of trade union & 1.78 & 6.08 \\
Knowlegde of labour rights & 1.9 & 7.8 \\
Knowledge of type of employment & 3.21 & 4.5 \\
\hline
\end{tabular}

\section{Key Contributions and Limitations of the Study}

This study presents some strengths that can be considered key contributors to the literature on the topic of organizational climate and migrants' working conditions.

Specifically, the main strengths concern the issue and the field of investigation. In Italy, studies on safety training have only recently been carried out, but these studies mainly addressed the working sector of construction $[58,63]$. Our study, although exploratory and still in the early stages of investigation, aims to broaden the field of the working sector, including in the training contents more focused on health and safety but also on some specific soft skills. Moreover, in an almost pioneering way in Italy, this paper integrated the literature on safety training, particularly in relation to migrant workers, the theoretical framework of realist evaluation, the transferability of training and its effectiveness.

An exploratory analysis of this kind could be of interest not only for the specific context in which the survey was carried out but also have a greater and cascading impact. The identification of the specific training needs of labor migrants, the characteristics of the training, and the difficulties that emerged in the transfer and application of the contents and skills learned could serve as a guide and stimulus for future research in this field. Involving a larger number of working migrants, but also their colleagues and especially employers, could be the perfect lock for a successful intervention.

Another strength of our study is the adoption of a purely qualitative approach. In fact, the objective posed was to understand in depth and in detail the perceptions and interpretations of the qualified witnesses [85]. Their points of view in fact provided a rich and complex interpretation of migrant workers' safety problems in their different working environments. Drawing on sensemaking theory as a framework [86] we analyzed how different significant actors gave meaning and interpreted their experiences, avoiding being subjected to various prejudices and stereotypes and making rash judgements or interpretations. Finally, the study represented one of the few attempts in Italy to measure the longitudinal impact of a training intervention. Future studies could add a third wave, including a further follow-up measurement at least 6 months after the intervention.

Despite the strengths of the present study, there are also some limitations to note. One of the limitations of the study could be found in the sample characteristics. A convenience sampling technique was used, which probably allowed us to reach only some workers, perhaps preventing the identification of the most vulnerable members of the workforce 
(i.e., those who have very limited language skills and/or whose immigration status is precarious). Therefore, the sample was not fully representative, either of the reference population or of possible occupations. Future research will certainly increase the sample in favor of resolving this limitation or at least reducing it.

Another limitation was represented by the very nature of focus groups and focused interviews, which should contain some pitfalls. The quality of qualitative research depends strongly on the individual skills of the researcher and is more easily influenced by his or her personal prejudices and idiosyncrasies. The researcher's presence during data collection could also influence the subjects' answers in some way, just as not being able to guarantee anonymity and confidentiality could be a problem in conducting the focus group and in the information that emerges. Despite this, the topic covered and the sample under examination required an approach of this nature, such that with the appropriate measures of rigor and technique the validity and reliability of the research was ensured [87]. The validity of research results referred to the degree to which the results are an accurate representation of the phenomena they are meant to represent, thus referring to the honesty and genuineness of the research data. The reliability of a study is related to the reproducibility and stability of the data, which has been extensively verified. In order to prove validity, a number of techniques were employed, such as the use of contradictory evidence, respondent validation and constant comparison. Specifically, contradictory evidence is used to ensure that the researcher's prejudices do not interfere with or alter their perception of the data and insights offered; these are implemented through the involvement of an additional moderator, who then monitors the work of the interviewer and the non-occurrence of counter-transference. Respondent validation, on the other hand, provides feedback from participants to check for inconsistencies in the interpretations of their responses, offering to the researchers the opportunity to re-analyze or correct the data. The use of constant comparison implies that a piece of data (e.g., an interview) is compared with previous data and not considered on its own, allowing researchers to treat the data as a whole rather than fragmenting it. Constant comparison also allows the researcher to identify emerging/anticipated themes within the research project.

Finally, this study involved one country and one region, so there is a need to replicate this study in other cultural contexts.

Overall, this study is an initial exploratory survey that may provide interesting insights for the academic community as well as stakeholders in the workplace, and serve as a guide and starting point for future studies.

\section{Discussion}

In the present study, we proposed a complex model that included several elements: on the one hand, we analyzed perceptions of diversity climate, safety climate and experiences of discrimination of migrant workers, and on the other hand, we verified the efficacy and the transfer of safety and soft skills training aimed at these workers.

Consistent with the invitations to move away from positivist approaches in construction labor sector research (e.g., [88,89]) we carried out an analysis of focus group and in-depth interview models in order to obtain rich insights regarding the working conditions of migrants and the possible effect of a training intervention. The results allowed us to address some important research questions and hypotheses posed.

The first research question, mainly related to the first three hypotheses of our work, concerned the understanding of the work situation experienced by migrants, meaning the challenges and possible key opportunities they faced regarding the discrimination they experienced, and their perception of the diversity and safety climate. As indicated by the data collected and as previously identified in the literature, migrant workers often did not have expertise in the work sectors in which they found work, and were often engaged in some of the most dangerous, dirty and onerous jobs. This means an unconditional and unconscious acceptance of these jobs, also due to their precarious situation. In addition, there were problems related to lack of knowledge and awareness. In addition to this, 
there are also issues related to lack of knowledge and awareness of safety regulations and attitudes, language barriers and various forms of discrimination. Our study focused mainly on the challenges of migrant workers and the training needs that this specific category of workers presented. Migrant workers, more than others, are exposed to an unequal climate of diversity, and are one of the most disadvantaged and at-risk groups when it comes to safety issues. The analysis addressed in this first part gives us the opportunity to closely observe and understand the experience of these workers, and to structure ad hoc interventions to improve their quality of life and promote a more virtuous society.

The study of the literature on the topic led us to structure a type of intervention with specific characteristics, which at the same time included principles on the safety and health of workers, but also considered the application of soft-skills (non-technical skills) as effective tools for the promotion and transferability of new knowledge and skills, also in the field of safety.

The second research question, corresponding to our hypotheses $\mathrm{H} 5$ and $\mathrm{H} 6$, focused in fact on the identification of the opportunities deriving from a training intervention of this type and the impact that this intervention could have both in the immediate future and in relation to the territory.

The findings, highly encouraging at the end of the training, lost some effectiveness in their impact on the territory, confirming the importance of an intervention involving all the actors in the territory. Colleagues, safety managers, employers and all stakeholders must be involved in order to create more awareness and attention on these issues, especially given the increasingly heterogeneous composition of work groups. We identified similar challenges and problems in the literature, especially regarding cultural awareness of safety regulations and language barriers, especially in the construction sector. An important finding from several studies is the role played by soft skills in supporting the implementation of safety and technical knowledge and skills, becoming important in ensuring the transfer of training. For this reason, the inclusion of soft skills in our training had a double value: on the one hand, it facilitated implementation and transferability to individual work contexts; on the other hand, it raised awareness and contributed to the creation of a set of skills that are useful in society and in relation to the current labor market, which is extremely flexible and constantly changing.

\section{Conclusions}

The results of this study bear a great deal of relevance and had an impact on several sectors. Practical examples of the applicability and use of these results could be found in the local area, in the process of change and reflection stimulated and in the possibility of achieving more ambitious goals such as a fair diversity climate, reduction of accidents and risks, and the achievement of good social sustainability.

The results obtained from this study and the recommendations that could resulted from them may be useful if properly adapted to improve the safety of migrant workers in a number of sectors (e.g., agriculture, industries) and also in a number of services such as hospitality, but also to increase employers' awareness of safety issues, discrimination and diversity climate. It is discussed that a training program, if efficient and transferred, leads to intended safety outcomes that depend on a variety of factors: individual characteristics, work environment factors and the content itself. Work environment seems to have the most important role, because it also mitigates the positive effects that the training has. In detail, proposing a training program for organizations and for stakeholders could be a solution to improve the positive effect and increase the applicability and transferability of all the contents of safety training. The study of Sherperd and colleagues [63] confirmed that including other groups in the study and training (key stakeholders, native colleagues and supervisors, safety experts and safety training) contributed to a broader view and greater efficacy in transferability. This result also emerged in our study, as the participants reported a difficulty in implementing the deliverable learning. In this paper, we also proposed a vision of the migrant worker as an active and participating actor of the training process. In 
effect, once these workers return to their workplace, they have to be proactive in changing their behaviors and seek out situations in which they can practice learned behaviors. In particular, with regard to safety, migrant workers often have to balance safety and time pressures [90], and suffer cultural and language barriers [40].

Conducting and presenting studies such as these are useful for local communities to stimulate reflection and awareness of the real issues and difficulties that migrant workers more than others experience. A good feedback of the results should also include widespread dissemination of what has emerged, in order to stimulate stakeholders on the general importance of promoting adequate training and positive climates of security and diversity. There were many studies confirming the important role played by the positive perception of these climates both from the individual point of view (greater self-efficacy, satisfaction, proactivity, involvement) and from the organizational point of view (greater productivity, greater significance given to work, better performance). Therefore, becoming aware of this means understanding the competitive advantage that could result [21,33]. In addition, an element that should never be underestimated is that the promotion of a positive climate of safety for migrant workers and a positive diversity climate will contribute to the achievement of many of the 17 Goals promoted by the 2030 Agenda for Sustainable Development, including social sustainability (good health and well-being, gender equality, decent work and economic growth, reduced inequalities, peace, justice and strong institutions).

Overall, this study is the beginning of a series of helpful studies to evaluate training aimed at migrants to promote their safety and inclusion, and improve their quality of life. The results achieved are quite encouraging and bear out the requirement for such training and the first positive effects on working conditions and quality of life. A more comprehensive and long-term study could involve further training and follow-up to allow us to measure variations over time. We hope to continue analysis and research in this field, and to inspire new forms of training and interventions, also including a wider range of participants. Safety training for migrants [91] is an issue that is still rarely discussed but is definitely useful not only for inclusion and better social adaptation, but in limiting risks and accidents in the workplace.

Author Contributions: Conceptualization, M.M. and L.B.; methodology, M.M.; formal analysis, M.M.; investigation, M.M. and L.B.; writing—original draft preparation, M.M. and L.B.; writing-review and editing, M.M. All authors have read and agreed to the published version of the manuscript.

Funding: This research received no external funding.

Institutional Review Board Statement: Not applicable.

Informed Consent Statement: Informed consent was obtained from all subjects involved in the study. Written informed consent has been obtained from the patients to publish this paper.

Data Availability Statement: Not applicable.

Conflicts of Interest: The authors declare no conflict of interest.

\section{References}

1. Burke, R.J.; Ng, E. The changing nature of work and organizations: Implications for human resource management. Hum. Resour. Manag. Rev. 2006, 16, 86-94. [CrossRef]

2. Downey, S.N.; van der Werff, L.; Thomas, K.M.; Plaut, V.C. The role of diversity practices and inclusion in promoting trust and employee engagement. J. Appl. Soc. Psychol. 2014, 45, 35-44. [CrossRef]

3. Statistiche Report Istat 2020. Available online: https://www.istat.it/it/files/2021/01/REPORT_MIGRAZIONI_2019.pdf (accessed on 28 December 2021).

4. Curry, O.; Smedley, C.; Lenette, C. What is "successful" resettlement? Refugee narratives from regional New South Wales in Australia. J. Immigr. Refug. Stud. 2018, 16, 430-448. [CrossRef]

5. Correa-Velez, I.; Barnett, A.G.; Gifford, S. Working for a better life: Longitudinal evidence on the predictors of employment among recently arrived refugee migrant men living in Australia. Int. Migr. 2015, 53, 321-337. [CrossRef]

6. Khawaja, N.G.; Hebbani, A. Does employment status vary by demographics? An exploratory study of former refugees resettled in Australia. Aust. Soc. Work 2018, 71, 71-85. [CrossRef] 
7. Nunn, C.; McMichael, C.; Gifford, S.M.; Correa-Velez, I. I came to this country for a better life': Factors mediating employment trajectories among young people who migrated to Australia as refugees during adolescence. J. Youth Stud. 2014, 17, 1205-1220. [CrossRef]

8. Naidoo, L.; Wilkinson, J.; Adoniou, M.; Langat, K. School to University transitions for Australian children of refugee background: A complex journey. In Transitions to Post-School Life: Responsiveness to Individual, Social and Economic Needs; Pavlova, M., Lee, J.C.-K., Maclean, R., Eds.; Springer: Singapore, 2018; pp. 81-103.

9. Afsharian, A.; Dollard, M.; Miller, E.; Puvimanasinghe, T.; Esterman, A.; De Anstiss, H.; Ziaian, T. Refugees at Work: The Preventative Role of Psychosocial Safety Climate against Workplace Harassment, Discrimination and Psychological Distress. Int. J. Environ. Res. Public Health 2021, 18, 10696. [CrossRef]

10. Baker, S.; Due, C.; Rose, M. Transitions from education to employment for culturally and linguistically diverse migrants and refugees in settlement contexts: What do we know? Stud. Contin. Educ. 2021, 43, 1-15. [CrossRef]

11. Mucci, N.; Traversini, V.; Giorgi, G.; Tommasi, E.; De Sio, S.; Arcangeli, G. Migrant workers and psychological health: A systematic review. Sustainability 2020, 12, 120. [CrossRef]

12. Jackson, S.; Bauder, H. Neither temporary, nor permanent: The precarious employment experiences of refugee claimants in Canada. J. Refug. Stud. 2014, 27, 360-381. [CrossRef]

13. Colic-Peisker, V. The 'visibly different' refugees in the Australian labor market: Settlement policies and emplyment realities. In Refugees, Recent Migrants and Employment Challenging Barriers and Exploring Pathways; McKay, S., Ed.; Routledge: New York, NY, USA, 2008.

14. Safdar, S.; Kosakowska-Berezecka, N.; Young, M.; Chan, Y.; Jacky, K. The psychological experience of refugees: A gender and cultural analysis. In Psychology of Gender through the Lens of Culture Theories and Applications, 1st ed.; Springer: Cham, Switzerland, 2015; pp. 17-36.

15. Due Billing, Y.D.; Sundin, E. From managing equality to managing diversity. A critical Scandinavian perspective on gender and workplace diversity. In Handbook of Workplace Diversity; Konrad, A.M., Prasad, P., Pringle, J.K., Eds.; Sage Publications: London, UK, 2006; pp. 95-121.

16. Puwar, N. Thinking about making a difference. Br. J. Politics Int. Relat. 2004, 6, 65-80. [CrossRef]

17. Shore, L.M.; Randel, A.E.; Chung, B.G.; Dean, M.A.; Ehrhart, K.H.; Singh, G. Inclusion and diversity in work groups: A reviewand model for future research. J. Manag. 2011, 37, 1262-1289. [CrossRef]

18. Pless, N.; Maak, T. Building an inclusive diversity culture: Principles, processes and practice. J. Bus. Ethics 2004, 54, 129-147. [CrossRef]

19. Mor Barak, M.E. Managing Diversity: Toward A Globally Inclusive Workplace, 2nd ed.; Sage: Thousand Oaks, CA, USA, 2005.

20. Thomas, D.A.; Ely, R.J. Making differences matter: A new paradigm for managing diversity. Harv. Bus. Rev. 1996, 74, 79-90.

21. Mor Barak, M.E.; Cherin, D.A.; Berkman, S. Organizational and Personal Dimensions in Diversity Climate. J. Appl. Behav. Sci. 1998, 34, 82-104. [CrossRef]

22. Chrobot-Mason, D.; Aramovich, N.P. The Psychological Benefits of Creating an Affirming Climate for Workplace Diversity. Group Organ. Manag. 2013, 38, 659-689. [CrossRef]

23. Howard-Grenville, J.A.; Hoffman, A.J.; Wirtenberg, J. The Importance of Cultural Framing to the Success of Social Initiatives in Business [and Executive Commentary]. Acad. Manage. Exec. 2003, 17, 70-86.

24. Jayne, M.E.A.; Dipboye, R.L. Leveraging diversity to improve business performance: Research findings and recommendations for organizations. Hum. Resour. Manag. 2004, 43, 409-424. [CrossRef]

25. McKay, P.F.; Avery, D.R.; Morris, M.A. Mean racial-ethnic differences in employee sales performance: The moderating role of diversity climate. Pers. Psychol. 2008, 61, 349-374. [CrossRef]

26. Bakker, L.; Cheung, S.Y.; Phillimore, J. The Asylum-Integration. Paradox: Comparing Asylum Support Systems and Refugee Integration in The Netherlands and the UK. Int. Migr. 2016, 54, 118-132. [CrossRef]

27. Thamrin, Y. A Literature Review of Migrant Workers' Health and Safety. J. Kesehat. Masy. Marit. Univ. Hasanuddin 2019, 1. [CrossRef]

28. Le, H.; Nielsen, K.; Noblet, A. The well-being and voice of migrant workers in participatory organizational interventions. Int. Migr. 2021, 1-20. [CrossRef]

29. Quandt, S.A.; Grzywacz, J.G.; Talton, J.W.; Trejo, G.; Tapia, J.; D’Agostino, R.B.; Mirabelli, M.C.; Arcury, T.A. Evaluating the Effectiveness of a Lay Health Promoter-Led, Community-Based Participatory Pesticide Safety Intervention With Farmworker Families. Health Promot. Pract. 2013, 14, 425-432. [CrossRef]

30. Zohar, D.; Tenne-Gazit, O. Transformational leadership and group interaction as climate antecedents: A social network analysis. $J$ Appl. Psychol. 2008, 93, 744-757. [CrossRef]

31. Zohar, D. Safety climate and beyond: A multi-level multi-climate framework. Safety Sci. 2008, 46, 376-387.

32. Neal, A.; Griffin, M.A. Safety climate and safety at work. In The Psychology of Workplace Safety; Barling, J., Frone, M.R., Eds.; American Psychological Association: Washington, DC, USA, 2004.

33. Fogarty, G.J.; Shaw, A. Safety climate and the Theory of Planned Behavior: Towards prediction of unsafe behavior. Acc. Anal. Prevent. 2010, 42, 1455-1459. [CrossRef]

34. Alruqi, W.M.; Hallowell, M.R.; Techera, U. Safety climate dimensions and their relationship to construction safety performance: A meta-analytic review. Saf. Sci. 2018, 109, 165-173. [CrossRef] 
35. Donaghy, R. One death is too many: Inquiry into the underlying causes of construction fatal accidents (Report to the Secretary of State for Work and Pensions. 2009; Volume 7657. Available online: https://www.gov.uk/government/uploads/system/ uploads/attachment_data/file/228876/7657.pdf (accessed on 2 February 2022).

36. Kranendonk, M.; De Beer, P. What Explains the Union Membership Gap between Migrants and Natives? Br. J. Ind. Relat. 2016, 54, 846-869. [CrossRef]

37. Marino, S.; Penninx, R.; Roosblad, J. Trade unions, immigration and immigrants in Europe revisited: Unions' attitudes and actions under new conditions. Comp. Migr. Stud. 2015, 3, 1. [CrossRef]

38. Hanley, J.; Paul, L.; Ravinthiran, J.; Malhaire, L.; Mosseau, N. Protecting the rights of migrant farmworkers in Quebec: To what extent can unionization overcome the effects of precarious immigration status? J. Rural. Community Dev. 2020, 15, 122-146.

39. Bretones, F.D.; Jain, A.; Leka, S.; García-López, P.A. Psychosocial Working Conditions and Well-Being of Migrant Workers in Spain. Int. J. Environ. Res. Public Health 2020, 17, 2547. [CrossRef]

40. Peiro, J.M.; Nielsen, K.; Latorre, F.; Shepherd, R.; Vignoli, M. Safety training for migrant workers in the construction industry: A systematic review and future research agenda. J. Occup. Health Psychol. 2020, 25, 275. [CrossRef]

41. López-Jacob, M.J.; Safont, E.C.; García, A.M.; Garí, A.; Agudelo-Suárez, A.; Gil, A.; Benavides, F.G. Participation and Influence of Migrant Workers on Working Conditions: A Qualitative Approach. New Solut. 2010, 20, 225-238. [CrossRef]

42. Flynn, M.A. Safety and the diverse workforce. Prof. Saf. 2014, 59, 52-57.

43. Orrenius, P.M.; Zavodny, M. Do immigrants work in riskier jobs? Demography 2009, 46, 535-551. [CrossRef]

44. Preibisch, K.; Otero, G. Does citizenship status matter in Canadian agriculture? Workplace health and safety for migrant and immigrant laborers. Rural Soc. 2014, 79, 174-199. [CrossRef]

45. Hsieh, Y.-C.; Apostolopoulos, Y.; Sönmez, S. Work conditions and health and well-being of Latina hotel housekeepers. J. Immigr. Minor. Health 2016, 18, 568-581. [CrossRef]

46. Liebman, A.K.; Wiggins, M.F.; Fraser, C.; Levin, J.; Sidebottom, J.; Arcury, T.A. Occupational health policy and immigrant workers in the agriculture, forestry, and fishing sector. Am. J. Ind. Med. 2013, 56, 975-984. [CrossRef]

47. Simon, J.; Kiss, N.; Łaszewska, A.; Mayer, S. Public Health Aspects of Migrant Health: A Review of the Evidence on Health Status for Labour Migrants in the European Region; WHO Regional Office for Europe: Copenhagen, Denmark, 2015. Available online: http:/ / www.euro.who.int/_data/assets/pdf_file/0003/289245/WHO-HEN-Report-A5-1-Labour-rev1.pdf?ua=1 (accessed on 2 February 2022).

48. O'Connor, T.; Loomis, D.; Runyan, C.; Abboud dal Santo, J.; Schulman, M. Adequacy of health and safety training among young Latino construction workers. J. Occup. Environ. Med. 2005, 47, 272-277. [CrossRef]

49. Grzywacz, J.G.; Arcury, T.A.; Marín, A.; Carrillo, L.; Coates, M.L.; Burke, B.; Quandt, S.A. The organization of work: Implications for injury and illness among immigrant Latino poultry-processing workers. Arch. Environ. Occup. Health 2007, 62, 19-26. [CrossRef]

50. International Labour Office. Work Related Stress: A Collective Challenge; Int. Labour Off.: Geneva, Switzerland, 2016.

51. Hsieh, Y.-C.J.; Sönmez, S.; Apostolopoulos, Y.; Lemke, M.K. Perceived workplace mistreatment: Case of Latina hotel housekeepers. Work 2017, 56, 55-65. [CrossRef] [PubMed]

52. Da Figueiredo, M.C.; Suleman, F.; do Carmo Botelho, M. Workplace abuse and harassment: The vulnerability of informal and migrant domestic workers in Portugal. Soc. Policy Soc. 2017, 17, 65-85. [CrossRef]

53. Cunningham, T.R.; Guerin, R.J.; Keller, B.M.; Flynn, M.A.; Salgado, C.; Hudson, D. Differences in safety training among smaller and larger construction firms with non- native workers: Evidence of overlapping vulnerabilities. Saf. Sci. 2018, 103, 62-69. [CrossRef] [PubMed]

54. Merton, R.K. The Matthew Effect in Science. Science 1969, 159, 59-63. [CrossRef]

55. Blume, B.D.; Ford, J.K.; Baldwin, T.T.; Huang, J.L. Transfer of training: A meta-analytic review. J. Manag. 2010, 36, 1065-1105. [CrossRef]

56. Forst, L.; Ahonen, E.; Zanoni, J.; Holloway-Beth, A.; Oschner, M.; Kimmel, L.; Sokas, R. More than training: Community-based participatory research to reduce injuries among Hispanic construction workers. Am. J. Ind. Med. 2013, 56, 827-837. [CrossRef]

57. Menzel, N.N.; Gutierrez, A.P. Latino worker perceptions of construction risks. Am. J. Ind. Med. 2010, 53, 179-187. [CrossRef]

58. Vignoli, M.; Nielsen, K.M.; Guglielmi, D.; Mariani, M.G.; Patras, L.; Peiro, J.M. Development of safety training for migrant workers in the construction industry. Saf. Sci. 2021, 136, 105124. [CrossRef]

59. Harrington, D.; Materna, B.; Vannoy, J.; Sholz, P. Conducting effective tailgate trainings. Health Promot. Pract. 2009, 10, 359-369. [CrossRef]

60. Jaselskis, E.J.; Strong, K.C.; Aveiga, F.; Canales, A.R.; Jahren, C. Successful multi- national workforce integration program to improve construction site performance. Saf. Sci. 2008, 46, 603-618. [CrossRef]

61. Health and Safety Executive (HSE). Contract Research Report 430/2002: Strategies to Promote Safe Behaviour as Part of a Health and Safety Management System. HSE, UK; 2002. Available online: https://www.hse.gov.uk/research/crr_pdf/2002/crr02430.pdf (accessed on 2 February 2022).

62. Hussain, R.; Pedro, A.; Lee, D.Y.; Pham, H.C.; Park, C.S. Impact of safety training and interventions on training-transfer: Targeting migrant construction workers. Int. J. Occup. Saf. Ergonom. 2020, 26, 272-284. [CrossRef] [PubMed]

63. Shepherd, R.; Lorente, L.; Vignoli, M.; Nielsen, K.; Peiro, J.M. Challenges influencing the safety of migrant workers in the construction industry: A qualitative study in Italy, Spain, and the UK. Saf. Sci. 2021, 142, 105388. [CrossRef] 
64. Mariani, M.G.; Vignoli, M.; Chiesa, R.; Violante, F.S.; Guglielmi, D. Improving Safety through Non-Technical Skills in Chemical Plants: The Validity of a Questionnaire for the Self-Assessment of Workers. Int. J. Environ. Res. Public Health 2019, 16, 992. [CrossRef] [PubMed]

65. Denzin, N.K.; Lincoln, Y.S. Introduction: The Discipline and Practice of Qualitative Research. In Handbook of Qualitative Research, 2nd ed.; Denzin, N.K., Lincoln, Y.S., Eds.; Sage Publications: Thousand Oaks, CA, USA, 2000.

66. Eklöf, N.; Hupli, M.; Leino-Kilpi, H. Planning focus group interviews with asylum seekers: Factors related to the researcher, interpreter and asylum seekers. Nurs. Inq. 2017, 24, e12192. [CrossRef] [PubMed]

67. Saunders, M.; Lewis, P.; Thornhill, A. Research Methods for Business Students, 8th ed.; Pearson: Hudson, NY, USA, 2019.

68. Fern, E. Advanced Focus Group Research; Sage Publications: Thousand Oaks, CA, USA, 2001.

69. Migliorini, L.; Rania, N. I focus group: Uno strumento per la ricerca qualitativa. Animazione Soc. 2001, 82-88.

70. Ramos, A.K.; McGinley, M.; Carlo, G. The relations of workplace safety, perceived occupational stress, and adjustment among Latino/a immigrant cattle feedyard workers in the United States. Saf. Sci. 2021, 139, 105262. [CrossRef]

71. Flynn, M.A. Im/migration, Work, and Health: Anthropology and the Occupational Health of Labor Im/migrants. Anthropol. Work Rev. 2018, 39, 116-123. [CrossRef]

72. Evia, C. Localizing and Designing Computer-Based Safety Training Solutions for Hispanic Construction Workers. J. Constr. Eng. Manag. 2011, 137, 452-459. [CrossRef]

73. Massenberg, A.-C.; Schulte, E.-M.; Kauffeld, S. Never too early: Learning Transfer System Factors Affecting Motivation to Transfer Before and After Training Programs. Hum. Resour. Dev. Q. 2017, 28, 55-85. [CrossRef]

74. Yelon, S.L.; Kevin Ford, J.; Bhatia, S. How trainees transfer what they have learned: Toward a taxonomy of use. Perform. Improv. Q. 2014, 27, 27-52. [CrossRef]

75. Huang, J.L.; Ford, J.K.; Ryan, A.M. Ignored no more: Within-person variability enables better understanding of training transfer. Pers. Psychol. 2017, 70, 557-596. [CrossRef]

76. Flin, R.; O'Connor, P.; Crichton, M. Safety at the Sharp End: A Guide to Non-Technical Skills; Ashgate Publishing Ltd.: Farnham, $\mathrm{UK}, 2008$.

77. Blume, B.D.; Kevin Ford, J.; Surface, E.A.; Olenick, J. A dynamic model of training transfer. Hum. Resour. Manag. Rev. 2019, 29, 270-283. [CrossRef]

78. Paolillo, A.; Silva, S.A.; Carvalho, H.; Pasini, M. Exploring patterns of multiple climates and their effects on safety performance atthe department level. J. Saf. Res. 2020, 72, 47-60. [CrossRef]

79. Paolillo, A.; Sinval, J.; Silva, S.A.; Scuderi, V.E. The Relationship between Inclusion Climate and Voice Behaviors beyond Social Exchange Obligation: The Role of Psychological Needs Satisfaction. Sustainability 2021, 13, 10252. [CrossRef]

80. Ruggiero, K.M.; Taylor, D.M. Why minority group members perceive or do not perceive the discrimination that confronts them: The role of self-esteem and perceived control. J. Pers. Soc. Psychol. 1997, 72, 373-389. [CrossRef]

81. Di Napoli, A.; Rossi, A.; Baralla, F.; Ventura, M.; Gatta, R.; Perez, M.; Sarchiapone, M.; Mirisola, C.; Petrelli, A. Self-perceived workplace discrimination and mental health among immigrant workers in Italy: A cross-sectional study. BMC Psychiatry 2021, 21, 85. [CrossRef]

82. Tobler, A.L.; Maldonado-Molina, M.M.; Staras, S.A.; O'Mara, R.J.; Livingston, M.D.; Komro, K.A. Perceived racial/ethnic discrimination, problem behaviors, and mental health among minority urban youth. Ethn. Health 2013, 18, 337-349. [CrossRef]

83. Dutta, M.J. Negotiating health on dirty jobs: Culture-centered constructions of health among migrant construction workers in Singapore. In Culture, Migration, and Health Communication in a Global Context; Yuping, M., Rukhsana, A., Eds.; Routledge: London, UK, 2017; pp. 45-59.

84. Ford, J.K.; Baldwin, T.P.; Prasad, J. Transfer of training: The known and the unknown. Annu. Rev. Organ. Psychol. Organ. Behav. 2018, 5, 201-225. [CrossRef]

85. Del Zotto, M. I testimoni qualificati in sociologia. In Costruire il Dato; Marradi, A., Ed.; Franco Angeli: Milan, Italy, 1988; pp. 132-144.

86. Weick, K.E.; Sutcliffe, K.M.; Obstfeld, D. Organizing the process of sensemaking. Organ. Sci. 2005, 16, 409-421. [CrossRef]

87. Anderson, C. Presenting and evaluating qualitative research. Am. J. Pharm. Educ. 2010, 74. [CrossRef]

88. Phelps, A.F.; Horman, M.J. Ethnographic theory-building research in construction. J. Constr. Eng. Manag. 2010, 136, 58-65. [CrossRef]

89. Zou, P.X.W.; Sunindijo, R.Y.; Dainty, A.R.J. A mixed methods research design for bridging the gap between research and practice in construction safety. Saf. Sci. 2014, 70, 316-326. [CrossRef]

90. Choudhry, R.M.; Fang, D. Why operatives engage in unsafe work behavior: Investigating factors on construction sites. Saf. Sci. 2008, 46, 566-584. [CrossRef]

91. Paolillo, A.; Silva, S.A.; Pasini, M. Promoting safety participation through diversity and inclusion climates. Int. J. Workpl. Health Manag. 2016, 9, 308-327. [CrossRef] 